Derecho y Realidad

Núm. 22 • II semestre de 2013

Facultad de Derecho y Ciencias Sociales, UPTC

ISSN: 1692-3936

\title{
El Sistema Interamericano de Protección de Derechos Humanos
}

\author{
The Inter-American System of Protection of \\ Human Rights
}

\author{
Víctor Rodríguez Rescia*
}

\section{Resumen}

La Declaración Americana de los Derechos y Deberes del Hombre de 1948, que sirve de marco para todo el sistema, cumple un papel importante para aquellos Estados miembros que todavía no han ratificado la Convención Americana, pero también para los Estados parte en ésta, porque opera como derecho consuetudinario y es una fuente de derecho fundamental, ya que incluso suple lagunas jurídicas como en el caso de los derechos económicos, sociales y culturales. Precisamente, en 1998 se celebró el quincuagésimo aniversario de este importante instrumento regional que además, para orgullo de los americanos, precedió por unos meses a la Declaración Universal de Derechos Humanos.

\section{Palabras clave}

Declaración Americana de los Derechos y Deberes del Hombre, Sistema Interamericano, Convención Americana, Declaración Universal de Derechos Humanos.

\footnotetext{
Consultor Externo del IIDH. Profesor universitario.
} 
276

Derecho y Realidad

\section{Abstract}

The American Declaration of the Rights and Duties of Man of 1948, which provides the framework for the whole system, plays an important role for those Member States that have not ratified the American Convention, but also to the States that are parties of it, because it operates as customary law and is a source of a fundamental right, as even supplies legal loopholes as in the case of economic, social and cultural rights. Indeed, 1998 marked the fiftieth anniversary of this important regional instrument that, also for the proud of Americans, preceded by a few months to the Universal Declaration of Human Rights.

\section{Key words}

American Declaration of the Rights and Duties of Man, the Inter-American Convention, Universal Declaration of Human Rights. 


\section{Introducción}

El sistema Interamericano de Protección de Derechos Humanos (en adelante "El Sistema Interamericano") no se puede entender en su completa dimensión si antes no tomamos en cuenta que su génesis se da dentro de un marco político regional, la Organización de los Estados Americanos (OEA), que permitió que los Estados Americanos que la conformaban tuvieran la visión de incluir dentro de su agenda un tema de la mayor vigencia en ese momento (1948).

Fue en el contexto de la finalización de la II Guerra Mundial que la comunidad internacional acuñó el término derechos humanos y lo plasma en instrumentos internacionales como la Carta de las Naciones Unidas.

A partir de ese momento, se inicia un proceso de progresividad ${ }^{1}$ en la promoción y protección de los derechos humanos en el contexto internacional, que parte de la aprobación de Declaraciones de Derechos Humanos hasta llegar a conformar sistemas más integrales y orgánicos en el marco de la aprobación de tratados generales y específicos de derechos humanos, incluyendo la creación de órganos, mecanismos y procesos internacionales de carácter judicial, cuasi judicial y de orden político.

Así, en la actualidad, el Sistema Interamericano se encuentra conformado por la Convención Americana sobre Derechos Humanos -como tratado general-, junto con sus protocolos sobre Derechos Económicos, Sociales y Culturales (Protocolo de San Salvador $)^{2}$ y el relativo a la abolición de la pena de muerte ${ }^{3}$, y las cuatro convenciones interamericanas sectoriales sobre: prevención y sanción de la tortura ${ }^{4}$, desaparición forzada de personas ${ }^{5}$, prevención, sanción y erradicación de la violencia

1 Parafraseando a Nikken (1987, p. 39), según el cual desde la aprobación de la Declaración Universal de 1948 se percibe una importante evolución de los instrumentos jurídicos creados con el fin de proteger los derechos humanos, y así se aprecia una tendencia progresiva de los mecanismos menos vigorosos hacia los que ofrecen un mayor grado de garantía y de fuerza vinculante.

2 Protocolo Adicional a la Convención Americana sobre Derechos Humanos en Materia de Derechos Económicos, Sociales y Culturales, "Protocolo de San Salvador". Suscrito en San Salvador, El Salvador, el 17 de noviembre de 1988, en el decimoctavo período ordinario de sesiones de la Asamblea General de la OEA. A la fecha no ha entrado en vigor.

3 Protocolo a la Convención Americana sobre Derechos Humanos relativo a la Abolición de la Pena de Muerte. Aprobado en Asunción, Paraguay, el 8 de junio de 1990, en el vigésimo período ordinario de la Asamblea General de la OEA. En vigor desde el 28 de agosto de 1991.

4 Convención Interamericana para Prevenir y Sancionar la Tortura. Suscrita en Cartagena de Indias, Colombia, el 9 de diciembre de 1985 en el decimoquinto período ordinario de sesiones de la Asamblea General de la OEA. En vigor desde el 28 de febrero de 1987.

5 Convención Interamericana sobre Desaparición Forzada de Personas. Adoptada en Belém do Pará Brasil, el 9 de junio de 1994, en el vigésimo cuarto período ordinario de la Asamblea General de la OEA. En vigor desde el 29 de marzo de 1996. 
contra la mujer ${ }^{6}$ y eliminación de discriminación contra personas con discapacidad ${ }^{7}$. Obviamente, la Declaración Americana de los Derechos y Deberes del Hombre de $1948^{8}$, que sirve de marco para todo el sistema, cumple un papel importante para aquellos Estados miembros que todavía no han ratificado la Convención Americana, pero también para los Estados parte en ésta, porque opera como derecho consuetudinario y es una fuente de derecho fundamental, ya que incluso suple lagunas jurídicas como en el caso de los derechos económicos, sociales y culturales. Precisamente, en 1998 se celebró el quincuagésimo aniversario de este importante instrumento regional que incluso, para orgullo de los americanos, precedió por unos meses a la Declaración Universal de Derechos Humanos.

Sin embargo, los antecedentes del Sistema Interamericano de Derechos Humanos son de más antigua data e, incluso, a veces ignoramos que constituyen precedentes vitales para el sistema universal de protección de derechos humanos ${ }^{9}$. Hablamos de la Declaración del Pueblo de Virginia de $1776^{10}$ y de la creación de la Corte Centroamericana de Justicia ${ }^{11}$, primer tribunal internacional regional, donde hasta se le reconocía participación directa a la persona (jus standi), situación que aún no es reconocida para el caso de la Corte Interamericana de Derechos Humanos ${ }^{12}$.

Cincuenta años después de haberse impulsado la creación del Sistema Interamericano, es tiempo suficiente para evaluarlo partiendo de que sus inicios se dieron dentro de un marco geopolítico que, en buena hora, se ha modificado: se ha pasado de un plano casi generalizado de gobiernos de facto hacia una democratización de los sistemas de gobierno, con las excepciones del caso.

6 Convención Interamericana para Prevenir, Sancionar y Erradicar la Violencia contra la Mujer “Convención de Belém do Pará."Adoptada en Belém do Pará, Brasil, el 9 de junio de 1994, en el vigésimo cuarto período ordinario de sesiones de la Asamblea General de la OEA. En vigor desde el 5 de marzo de 1995.

7 Convención Interamericana para la Eliminación de Todas la Formas de Discriminación contra las Personas con Discapacidad. Adoptada durante la Primera Sesión Plenaria de la Asamblea General de la OEA, el 7 de junio de 1999.

8 Aprobada en la Novena Conferencia Internacional Americana, Bogotá, Colombia, 1948.

9 Remontándonos a tiempos más remotos, resulta ilustrativo recordar que América tiene su propia historia en materia de derechos humanos. Cabe destacar el esfuerzo desplegado por Fray Bartolomé de las Casas por establecer la unidad del género humano, antecedente necesario para afirmar que "los hombres nacen libres y permanecen libres e iguales en derechos", lo que a la postre fue un corolario de la Revolución Francesa.

10 La Declaración del Buen Pueblo de Virginia fue el primer instrumento sobre derechos humanos de carácter general y no la Declaración de los Derechos del Hombre y del Ciudadano de la Revolución Francesa.

11 Creada por el Pacto de Washington en 1907 e instalada en San José, Costa Rica, en 1908. Operó hasta 1918.

12 De acuerdo con el artículo 61.1 de la Convención Americana, "[s]ólo los Estados partes y la Comisión tienen derecho a someter un caso a la decisión de la Corte". 
Se pretende con este documento hacer un estudio sobre el Sistema Interamericano, sus antecedentes, órganos de promoción y protección, funcionamiento y mecanismos y procedimientos vigentes, pasando por una evaluación del sistema y sus nuevos retos y desafíos.

\section{Antecedentes del sistema Interamericano}

Los derechos humanos en general, no pueden abstraerse de las circunstancias sociopolíticas del momento. Ello debido a que, en principio, sólo los Estados -técnicamente hablando- cometen violaciones a los derechos humanos y son ellos mismos los que crean y aprueban los instrumentos legales para su protección (tanto internos como internacionales). Así, los sistemas de protección internacional se crean, necesariamente, dentro de un marco político regional o universal, donde la forma en que la comunidad internacional se encuentre organizada juega un papel medular. Así por ejemplo, es notable la dificultad para establecer un sistema regional de protección de derechos humanos en el continente asiático debido a la ausencia de una organización política regional fuerte que sirva de marco referencial para la discusión y aprobación de los instrumentos internacionales adecuados y que, además, puedan resultar eficaces.

El Sistema Interamericano tiene la peculiaridad de que sus antecedentes son los de más vieja data de los sistemas regionales, con la excepción del europeo (Nieto, 1993, p. 9). Es a partir del Congreso Anfictiónico de Panamá (1826) que se desencadena una serie de Congresos y Conferencias Interamericanas en las que se desarrollan los principios del panamericanismo y los ideales bolivarianos ${ }^{13}$.

Cuando se realiza la Conferencia Interamericana sobre los Problemas de la Guerra y la Paz, en Chapultepec, México, 1945, ya el sistema regional americano tenía más de un siglo de desarrollo. Fue en ese momento que se establecieron las bases para pasar de la Unión Panamericana a una Organización de Estados Americanos fortalecida y bien organizada políticamente, lo cual permitió trabajar en forma pionera en la protección regional de los derechos humanos y, además, jugar un papel relevante en lo que sería la creación de la Organización de las Naciones Unidas, no sólo por lo numeroso de los Estados americanos, sino por la experiencia desarrollada y por los principios de solidaridad puestos en práctica ante situaciones de agresión de potencias extranjeras experimentada a lo largo de su historia, especialmente, en las postrimerías de la independencia de España.

El momento culminante de este proceso fue la Novena Conferencia Internacional Americana celebrada en Bogotá, Colombia, en 1948. Además de una serie de

$\overline{13}$ Un análisis detallado sobre el desarrollo del sistema interamericano puede verse en Nieto (1993). 
acuerdos vitales para el sistema interamericano, en dicha Conferencia se creó la Carta de la OEA y la Declaración Americana sobre Derechos y Deberes del Hombre. Sólo un bagaje regional tan vasto como el americano podría hacer posible la promulgación de tantos instrumentos internacionales en una sola reunión internacional.

En 1959 se crea una Comisión Interamericana de Derechos Humanos con funciones de promoción y protección de derechos humanos, pero con mayor énfasis en promoción porque no tenía competencia para tramitar quejas individuales. Ya para 1965, se le ampliaron sus funciones para que pudiera recibir denuncias individuales mediante el Protocolo de Río de Janeiro. En 1967, el Protocolo de Buenos Aires dio a la Comisión carácter de órgano de la OEA.

El artículo 145 de la Carta de la OEA, reformada por dicho Protocolo, quiso dejar clara la naturaleza y fines de la Comisión al estipular que "[m]ientras no entre en vigor la convención interamericana sobre derechos humanos a que se refiere el capítulo XV, la actual Comisión Interamericana de Derechos Humanos velará por la observancia de tales derechos".

Con sus nuevas funciones, le correspondió a la Comisión Interamericana elaborar un proyecto de Convención Americana sobre Derechos Humanos y se convocó a una Conferencia especializada sobre la materia para 1969 en San José, Costa Rica, la cual tuvo por resultado la emisión de dicha Convención, que entró en vigor sólo en 1978, cuando se hizo el depósito del undécimo instrumento de ratificación.

Es así como con la entrada en vigor de la Convención Americana, el Sistema Interamericano de Protección de Derechos Humanos se transformó en un sistema dual, con dos regímenes distintos, no sólo en cuanto a los derechos protegidos, sino respecto a los órganos y procedimientos de protección. El primer sistema es el aplicable a los Estados miembros de la OEA que no hayan ratificado la Convención Americana y el otro es exclusivo para los Estados que sí la han ratificado (Estados Parte en la Convención).

En síntesis, podemos decir que el Sistema Interamericano se caracteriza por mantener una progresividad en cuanto a la protección de los derechos humanos en el continente, que se puede resumir en el siguiente proceso:

1) Se adoptó la Declaración Americana sobre Derechos y Deberes del Hombre por medio de un órgano político de la $\mathrm{OEA}^{14}$. Si bien surgió como una

\footnotetext{
14 Fue adoptada por la Novena Conferencia Internacional Americana (Bogotá, 1948), en virtud de una resolución tomada por la propia Conferencia.
} 
declaración de principios, la misma práctica de los Estados miembros le ha otorgado un valor jurídico más allá de una mera recomendación. Sobre el valor jurídico de la Declaración Americana, la Corte Interamericana se refirió en forma clara a dicho punto en su opinión consultiva OC-10/89.

2) Fue sólo en 1959 que, durante la 5ta. Reunión de Consulta de Ministros de Relaciones Exteriores, celebrada en Chile, se creó la Comisión Interamericana de Derechos Humanos, la cual inició funciones a partir de 1960, cuando se aprobó su Estatuto.

3) Durante la $2^{\text {a }}$ Conferencia Interamericana en Río de Janeiro, 1965, se ampliaron las facultades de la Comisión Interamericana de Derechos Humanos para que pudiera recibir comunicaciones o quejas individuales.

4) En la $3^{\text {a }}$ Conferencia Interamericana en Buenos Aires de 1967, se aprueba un Protocolo de reformas a la Carta de la OEA con el fin de incluir a la Comisión como un órgano más de ella. Además, se instó a crear una "Convención Interamericana de Derechos Humanos" para 1969.

5) Fue en 1969 cuando se adopta la Convención Americana sobre Derechos Humanos vigente, cuya mayor virtud es darle carácter convencional a la protección de los derechos humanos en las Américas y crear órganos y mecanismos de protección con competencia más amplia y precisa para garantizar una mayor eficacia jurídica. Con la entrada en vigor de dicho instrumento en 1978, es que se plantea la doble estructura del Sistema Interamericano por la existencia de cuatro distintos regímenes, según sea que los Estados hayan ratificado o no determinados tratados regionales de derechos humanos:

a. Un régimen dirigido a Estados no ratificantes de la Convención Americana, que es el mismo utilizado antes de 1965 para aquellos Estados que únicamente eran miembros de la OEA y a los cuales se les aplica la Declaración Americana (Estados Unidos de América, Canadá y algunos países del Caribe).

b. Un régimen para los Estados ratificantes de la Convención Americana mediante el cual se instrumentan dos órganos de protección: la Comisión Interamericana de Derechos Humanos (que ya existía, pero se redefinieron sus funciones en el Pacto de San José) y la Corte Interamericana de Derechos Humanos.

c. Otro régimen para aquellos Estados que hayan ratificado la Convención Americana pero que, además, han aceptado la competencia jurisdiccional de la Corte. Este es el sistema más amplio de protección al cual se han sumado todo los países latinoamericanos y algunos pocos del Caribe. Por eso, la mayor preocupación es la necesidad de universalizar el Sistema Interamericano para 
que aquellos países de tradición anglosajona que no lo hayan hecho, ratifiquen la Convención Americana y acepten la competencia de la Corte Interamericana. d. Hay una especie de cuarta situación sui generis que es el caso de Cuba, cuyo gobierno de Fidel Castro -no el Estado, que es el verdadero sujeto de Derecho Internacional- fue expulsado de la OEA conforme al artículo 1 de la Carta de la OEA, pero no por ello queda exento el Estado de cumplir con las obligaciones estipuladas en la Declaración Americana de 1948, lo que incluso ha dado paso a la formulación de varios informes de la Comisión Interamericana sobre la situación de los derechos humanos en ese país.

\section{Instrumentos Interamericanos más recientes referidos a los derechos humanos}

Dentro del marco de la Asamblea General de la OEA de 1985, que aprobó el Protocolo de Cartagena de Indias, el cual enmendó la Carta de esa Organización, los Estados miembros abrieron para la firma la Convención Interamericana para Prevenir y Sancionar la Tortura.

Este instrumento establece una detallada definición sobre la tortura e indica quiénes serían los responsables de este delito. Los Estados partes no sólo se comprometen a castigar severamente a los perpetradores de la tortura sino, además, a tomar medidas para prevenir y sancionar cualquier otro trato cruel, inhumano o degradante dentro de sus jurisdicciones. Así, una persona acusada de cometer tortura no puede evitar su castigo huyendo al territorio de otro Estado parte, bajo los términos de esta Convención.

Esta Convención entró en vigencia el 28 de febrero de 1987, treinta días después del depósito del segundo instrumento de ratificación. Como aspecto por resaltar, la Corte Interamericana también tiene competencia para determinar violaciones a este nuevo tratado y ya no solo respecto de la Convención Americana sobre Derechos humanos. Precisamente, en el caso Paniagua Morales y otros contra Guatemala, la Corte Interamericana (1998), por primera vez, determinó que dicho Estado, además de haber violado el artículo 5 de la Convención Americana referente a la tortura, lo hizo también en relación con los artículos 1, 6 y 8 de la Convención Interamericana para Prevenir y Sancionar la Tortura.

El Protocolo a la Convención Americana sobre Derechos Humanos relativo a la Abolición de la Pena de Muerte, fue aprobado en el vigésimo período ordinario de sesiones de la Asamblea General de la OEA (Asunción, Paraguay, 1990). Su génesis se remonta a 1969, cuando se redactaba la Convención Americana sobre Derechos Humanos, donde no tuvo éxito un esfuerzo concertado para incluir una provisión que hubiera prohibido absolutamente la pena capital. Este instrumento aboliría la 
pena de muerte a lo largo de todo el hemisferio mediante la ratificación del Protocolo por los Estados partes.

Durante la vigésimo cuarta sesión ordinaria de la Asamblea General de la OEA, celebrada en Belém do Pará, Brasil, se aprobó la Convención Interamericana sobre Desaparición Forzada de Personas, la cual entró en vigor el 28 de marzo de 1996, treinta días después del depósito del segundo instrumento de ratificación.

Este instrumento establece una detallada definición de la desaparición forzada e indica quiénes son los responsables de este delito. Los Estados Partes se comprometen no sólo a no practicar, permitir, o tolerar la desaparición forzada sino también a sancionar a los autores, cómplices y encubridores de este delito dentro de sus jurisdicciones; se comprometen a adoptar las medidas legislativas para tipificar la desaparición forzada como delito y a cooperar entre sí para contribuir a prevenir, sancionar y erradicar tales desapariciones tomando las medidas necesarias para cumplir con los compromisos de la Convención. Asimismo, tipifica el delito entre aquellos que justifican la extradición, para que una persona acusada del delito no evite su castigo al huir al territorio de otro Estado Parte.

También, durante la vigésimo cuarta sesión ordinaria de la Asamblea General de la OEA celebrada en Belém do Pará, Brasil, se aprobó la Convención Interamericana para Prevenir, Sancionar y Erradicar la Violencia contra la Mujer (Convención de Belém do Pará, la cual entró en vigor el 5 de marzo de 1995, treinta días después del depósito del segundo instrumento de ratificación.

Este instrumento establece una detallada definición de la violencia contra la mujer, incluyendo la violencia física, sexual y psicológica y establece que toda mujer tiene derecho a una vida libre de violencia, además de todos los derechos humanos consagrados por los instrumentos regionales e internacionales. Los Estados Partes condenan todas las formas de violencia contra la mujer y convienen en adoptar tanto políticas como medidas específicas orientadas a prevenir, sancionar y erradicar dicha violencia.

Finalmente, durante la Asamblea General de la OEA de 1999, se aprobó la Convención Interamericana para la Eliminación de todas las Formas de Discriminación contra las Personas con Discapacidad, a partir de la preocupación de que la discapacidad puede dar origen a situaciones de discriminación, lo que implica tomar acciones que permitan mejorar sustancialmente su situación. Para esos fines, los Estados se comprometieron a adoptar las medidas de carácter legislativo, social, educativo, laboral o de cualquier otra índole, necesarias para eliminar la discriminación contra las personas con discapacidad y propiciar su plena integración en la sociedad, 
Derecho \& Realidad

\section{Los órganos de protección del sistema}

\section{La Comisión Interamericana de Derechos Humanos}

La Comisión Interamericana fue creada por la $5^{\text {a }}$ Reunión de consulta de Ministros de Relaciones Exteriores en Santiago de Chile, 1959. El 25 de mayo de 1960 el Consejo de la OEA aprobó su primer Estatuto y lo enmendó en junio de 1960, fecha en la cual inicia sus labores. Su sede se encuentra en Washington D.C.

La Comisión está conformada por siete miembros (comisionados) de la nacionalidad de alguno de los Estados miembros de la OEA, pero no representan a su país, sino que son elegidos por la Asamblea General de la OEA a título personal. Como la Comisión es un órgano de promoción y protección, pero no de carácter judicial, sino cuasi judicial, no se requiere ser jurista para ser designado miembro, a diferencia de la Corte Interamericana donde sí es un requisito necesario.

La Comisión no es un órgano permanente, sino que se reúne varias veces al año, dependiendo del presupuesto anual que le haya designado la OEA, razón por la cual, el peso administrativo y logístico recae en su Secretaría y el personal profesional, que sí se mantienen trabajando regularmente. Sin embargo, debido a la cantidad de trabajo, denuncias que recibe (alrededor de 1000 peticiones individuales), visitas que debe hacer a los países para la emisión de informes específicos, etc., sus recursos financieros y humanos nunca son los adecuados para brindar un servicio idóneo para una competencia que abarca a 35 países de la región, incluyendo a Cuba.

La génesis de la Comisión va de la mano con que la OEA no deseaba crear un órgano regional que interfiriera con los asuntos internos de los Estados Miembros. Se pretendía originalmente que realizara actividades de promoción y educación en derechos humanos a partir de la realización de estudios, simposios, reuniones sobre asuntos generales, pero sin inmiscuirse en la observancia de los derechos humanos en países específicos.

Sin embargo, la misma Comisión interpretó que se le había otorgado la función de velar por la protección de los derechos humanos, defenderlos y promover su observancia. Era obvio que para ello, las facultades que se le concedieron eran insuficientes para realizar esas funciones. Así, la Comisión inició la realización de actividades no contempladas explícitamente en su Estatuto pero consideraba que implícitamente eran necesarias para el mejor cumplimiento de sus funciones. Precisamente, fue el sometimiento de numerosas quejas contra los gobiernos, lo que estimuló a la Comisión a realizar una interpretación extensiva de su Estatuto. 
La OEA no cuestionó esos procedimientos lo que implicó una aceptación tácita de su validez.

Esta evolución culminó con la intervención de la Comisión en el caso de la República Dominicana que la transformó de un "grupo de estudios" en un órgano de la OEA para la protección de los derechos humanos.

Bajo ese esquema, la principal función que tuvo la Comisión fue enfrentar el problema de las violaciones masivas y sistemáticas de los derechos humanos (Somoza en Nicaragua, Stroessner en Paraguay, eliminación de partidarios de Batista en Cuba en 1960) y no la de investigar violaciones aisladas, que era como funcionaba el sistema europeo. Ello con el fin de documentar la existencia de las violaciones y presionar para mejorar la situación general de los derechos humanos en el país que se tratara. Para poder obtener efectos positivos, el procedimiento se caracterizó por su flexibilidad para poder "tomar conocimiento" de las denuncias de violaciones de derechos humanos, pedir informaciones al Gobierno y formularle recomendaciones finales. A grandes rasgos, las características de ese proceso, antes de que entrara en vigor la Convención Americana, eran las siguientes:

- Poner en movimiento el procedimiento sin examinar requisitos de admisibilidad de la denuncia.

- Ejercer un papel muy activo para pedir información e investigar por todos los medios a su alcance (testigos, periódicos, ONG, visitas in situ, etc.).

- Publicitar los hechos para presionar a los gobiernos.

- Enviar el resultado de la investigación a los órganos políticos de la OEA para su discusión y aprobación.

- No era necesario agotar los recursos de la jurisdicción interna.

Después ${ }^{15}$, se autorizó a la Comisión para conocer y examinar comunicaciones individuales, investigarlas y formular recomendaciones al Estado. A diferencia de la etapa anterior, en esta nueva fase sí se requería verificar, como medida previa, el agotamiento de los recursos internos. Este requisito dio al traste con la práctica flexible que la Comisión venía desarrollando y representó un obstáculo a la principal función de la Comisión al retrasar una rápida respuesta de la Comisión a una situación de violación seria y sistemática de derechos humanos. Igualmente, se acentuó el carácter cuasi judicial de la Comisión, lo que le quitó flexibilidad para investigar por su propia cuenta ${ }^{16}$.

15 En 1965, mediante la Resolución XXII de la $2^{\text {a }}$ Conferencia Extraordinaria de la OEA.

16 Ello a pesar del numeral 24 del Reglamento de la Comisión que dispone: "La Comisión podrá, motu proprio, iniciar la tramitación de una petición que contenga, a su juicio, los requisitos para tal fin”. 
La solución para este desfase procesal fue agregar al Estatuto de la Comisión el artículo 9 (bis) para conservar el procedimiento flexible, por una parte, y agregar el nuevo (cuasi-judicial) para conocer de violaciones de ciertos derechos humanos establecidos como fundamentales en la Resolución XXII (arts. I, II, III, IV, XVIII, XXV y XXVI de la Declaración Americana). Este proceso resultó ser más técnico porque además del agotamiento de los recursos internos, debía presentarse la denuncia dentro de los plazos establecidos y la Comisión emitía una opinión denunciando una violación de los derechos humanos a la par de recomendaciones dirigidas al Estado.

En 1967 se aprobó el Protocolo de Buenos Aires durante la $3^{\text {a }}$ Conferencia Interamericana Extraordinaria. Con ello se dio el paso necesario para el fortalecimiento institucional de la Comisión al modificarse el artículo 51 de la Carta e incluirla como un órgano más de la OEA. No obstante, no se le concedieron nuevas atribuciones.

\section{Derechos por proteger}

El artículo 1.2 del Estatuto de la Comisión establece que "por derechos humanos se entiende los consagrados en la Declaración Americana de Derechos y Deberes del Hombre y en la Convención Americana sobre Derechos Humanos”. Algunos han tratado de desvirtuar el carácter vinculante de los derechos contemplados en la Declaración Americana y se le ha contrastado incluso con la Convención Americana, por ser esta un tratado internacional propiamente dicho y aquella no ${ }^{17}$. Lo cierto es que al haber sido adoptada unánimemente por los Estados ligados a la Carta de la

\footnotetext{
17 Ilustrativa es la posición de los Estados Unidos de América en sus observaciones al proceso consultivo OC-10/89 ante la Corte Interamericana, cuando manifestó: "[I]a Declaración Americana de los Derechos y Deberes del Hombre representa una noble enunciación de las aspiraciones de los Estados Americanos en cuanto a los derechos humanos... Sin embargo, a diferencia de la Convención Americana, no fue redactada como un instrumento jurídico y carece de la precisión necesaria para resolver complejas dudas legales. Su valor normativo estriba en ser una declaración de principios básicos de carácter moral y de carácter político y en ser la base para velar por el cumplimiento general de los derechos humanos por parte de los Estados Miembros; no en ser un conjunto de obligaciones vinculantes..." Por su parte, el Estado de Costa Rica, en una desacertada y contradictoria opinión, muy diferente a la posición garantista que siempre la ha caracterizado (primer Estado en ratificar la Convención Americana y en aceptar la competencia contenciosa de la Corte), expresó: “... no obstante el gran acierto y la nobleza que conlleva la Declaración Americana de los Derechos y Deberes del Hombre, no se está en presencia de un tratado en el sentido establecido por el Derecho Internacional, de modo que el artículo 64 de la Convención Americana no faculta a la Corte Interamericana para interpretar la Declaración. Sin embargo, ello de ninguna manera podría menoscabar la posibilidad de que la Corte utilice la Declaración y los preceptos ahí incorporados para interpretar otros instrumentos jurídicos relacionados ni para considerar que muchos de los derechos ahí reconocidos sean elevados a la categoría indiscutible de costumbre internacional“. (Subrayado no es del original). Interpretación de la Declaración Americana de los Derechos y Deberes del Hombre en el marco del artículo 64 de la Convención Americana sobre Derechos Humanos, Opinión Consultiva OC-10/89 del 14 de julio de 1989. Serie A No. 10, párrs. 11, 12.
} 
OEA, la Declaración tiene también un irrefutable carácter vinculante ${ }^{18}$, además de ser fuente de derecho internacional al ser invocada constantemente por los Estados, tanto en foros internacionales como para informar la jurisprudencia.

Además, la Comisión Interamericana (al igual que la Corte Interamericana), tienen una competencia ampliada para interpretar "otros tratados concernientes a la protección de los derechos humanos en los Estados Americanos" ${ }^{19}$. En su opinión consultiva OC-1/82, la Corte Interamericana interpretó la frase "otros tratados" citada, de la siguiente manera: "la competencia consultiva de la Corte puede ejercerse, en general, sobre toda disposición, concerniente a la protección de los derechos humanos, de cualquier tratado internacional aplicable en los Estados americanos, con independencia de que sea bilateral o multilateral, de cuál sea su objeto principal o de que sean o puedan ser partes del mismo Estados ajenos al sistema interamericano" ${ }^{20}$ (subrayado no es del original).

Actualmente, las funciones y competencia de la Comisión son las más amplias que pueda tener un órgano de promoción y protección de derechos humanos, especialmente porque puede vigilar y promover los derechos humanos desde todas las ópticas posibles y no solo desde la tramitación de casos concretos. Por ejemplo, puede realizar investigaciones sobre violaciones flagrantes y sistemáticas. Por ello, debe tener el personal suficientemente capacitado para vigilar los derechos humanos desde un punto de vista integral y no solo jurídico; puede hacer recomendaciones a los Estados Americanos sobre políticas públicas en distintos temas sobre derechos humanos (ausencia de políticas o falta de idoneidad de las existentes), promover reformas legislativas para adecuar la legislación interna a los instrumentos interamericanos, servir de observatorio regional de la situación de los derechos humanos, emitir informes anuales y específicos, servir de órgano consultor de la OEA en materia de derechos humanos, educar en la materia, redactar y dar seguimiento de proyectos de declaraciones y tratados sobre derechos humanos, etc.

18 En la Opinión Consultiva OC-10/89, la Corte Interamericana dispuso: "Estas normas (arts. 112 y 150 de la Carta de la OEA) atribuyen a la Comisión Interamericana la competencia de velar por los derechos humanos y estos derechos no son otros que los enunciados y definidos en la Declaración Americana... La Asamblea General de la Organización ha reconocido además, reiteradamente, que la Declaración Americana es una fuente de obligaciones internacionales para los Estados Miembros de la OEA". Interpretación de la Declaración Americana de los Derechos y Deberes del Hombre en el marco del artículo 64 de la Convención Americana sobre Derechos Humanos, Opinión Consultiva OC-10/89 del 14 de julio de 1989. Serie A No. 10, párrs. 41, 42.

19 El artículo 111 de la Carta de la OEA reformada establece: "[h]abrá una Comisión Interamericana de Derechos Humanos que tendrá como función principal la de promover la observancia y la defensa de los derechos humanos y de servir como órgano consultivo de la Organización en esta materia..." (Subrayado no es del original). Ver asimismo, Convención Americana sobre Derechos Humanos, artículo 64.1.

20 Corte IDH. Opinión Consultiva OC-1, "Otros Tratados" objeto de la función consultiva de la Corte (artículo 64 Convención Americana sobre Derechos Humanos. Punto resolutivo primero. 
Pero quizás, una de las funciones que más tiempo y recursos le demandan es la tramitación de peticiones o comunicaciones individuales, ya que el procedimiento interamericano exige que, para que un caso pueda ser conocido por la Corte Interamericana, debe necesariamente pasar antes por el procedimiento ante la Comisión dispuesto en la Convención Americana, el cual es irrenunciable ${ }^{21}$.

Funciones específicas

De acuerdo con el artículo 19 de su Estatuto, entre otras funciones, le corresponde a la Comisión:

a) Estimular la conciencia de los derechos humanos en los pueblos de América.

b) Formular recomendaciones a los gobiernos para que adopten medidas progresivas.

c) Preparar estudios o informes que considere convenientes para el desempeño de sus funciones.

d) Solicitar informes a los gobiernos sobre las medidas que adopten en materia de derechos humanos.

e) Servir como cuerpo asesor de la OEA en materia de derechos humanos.

Otras funciones que tiene la Comisión son las referentes al examen de la situación general de los derechos humanos en un Estado (Country Reports). Las características de este procedimiento son:

- Todos los Estados miembros de la OEA están sujetos a este examen.

- No existe un procedimiento ordenado de normas para hacer los exámenes pero la práctica ha sido consistente en cuanto a su origen, a saber:

a) Se puede iniciar por la existencia de un número considerable de comunicaciones individuales que justifican hacer una investigación general $\left(1^{\circ}\right.$ Informe sobre Chile).

b) A petición de algún órgano de la OEA (Informe sobre Bolivia a pedido del Consejo Permanente).

c) A petición del mismo Estado miembro (Informe sobre Panamá).

d) Como seguimiento por la Comisión de un informe emitido con anterioridad $\left(2^{\circ}\right.$ Informe sobre Suriname o los Informes sobre Cuba).

\section{Los informes sobre países}

Los informes sobre países es una de las funciones más importantes de la Comisión

21 Jurisprudencia desarrollada por la Corte Interamericana desde los inicios de su gestión en el Asunto de Viviana Gallardo y otros contra Costa Rica. 
Interamericana, debido a la trascendencia de la visita y el análisis general que se hace sobre la situación de los derechos humanos en el mismo. La iniciativa para elaborarlo puede ocurrir por las siguientes vías:

a) Petición de informes al Estado o a otras instituciones gubernamentales.

b) Audiencias de testigos y expertos.

c) Comunicaciones individuales.

d) Observaciones in loco (la Comisión pide permiso al Estado o le sugiere que la invite).

e) Entrevistas públicas o privadas de personas, grupos o instituciones.

f) Visitas a cárceles y entrevistas a detenidos en privado.

g) Mediación para la resolución de casos específicos.

El procedimiento de los informes sobre países tiene varias fases:

- Se realiza un informe preliminar con un patrón uniforme: se describe y analiza el sistema político y legal del país y se estudia cada uno de los derechos que a la Comisión le interesa investigar a partir de los hechos denunciados.

- Se analizan normas legales internas en relación con los instrumentos internacionales regionales en derechos humanos.

- Se ilustra la situación general con casos individuales que la Comisión esté conociendo.

- No se hace un análisis rigurosamente técnico.

- No se mencionan nombres de las víctimas ni testigos, a diferencia de los casos individuales, donde el sistema es fundamentalmente reparador. El informe termina con conclusiones y recomendaciones específicas y, en algunos casos, políticas (en Colombia se recomendó al Gobierno cumplir con el pago de $10 \%$ del presupuesto para el Poder judicial, retornar o perfeccionar la democracia, etc.).

- Se da traslado del informe al Gobierno para que haga observaciones y luego, la Comisión mantiene el informe o lo modifica debido a la información que le haya transmitido el Estado.

- Elaboración del informe definitivo: Se publica si la Comisión lo decide y se envía a la OEA u ocasionalmente se envía a la Reunión de Consulta de Ministros de Relaciones Exteriores (Informe sobre Nicaragua 1978).

Hasta 1976 ningún órgano político de la OEA había discutido los informes sobre violaciones masivas y sistemáticas. Del año 1976 a 1980, la OEA los discutió exhaustivamente y condenó a los Estados pero sin tomar medida alguna. Después de 1980 se decidió no condenar a ningún país específico y se hace referencia sólo a violaciones de manera autónoma. 
Derecho y Realidad

Algunos casos en que ha ocurrido una discusión amplia son:

1. Resolución VI de la $8^{\text {a }}$ Reunión de Consulta de Ministros de Relaciones Exteriores, Punta del Este, 1962 que declaró al Gobierno de Fidel Castro incompatible con los principios y propósitos del sistema interamericano y excluyó su participación del sistema (aún cuando el Estado debe continuar asumiendo sus obligaciones internacionales, lo que ha generado informes sobre dicho país).

2. Resolución II de la $17^{\text {a }}$ Reunión de Consulta, 1979, que pidió el reemplazo del Gobierno de Somoza en Nicaragua.

En ambos casos la Comisión Interamericana adoptó medidas diplomáticas.

\section{La Comisión después de la Convención Americana}

Con la entrada en vigor de la Convención Americana y con la modificación aparejada de la estructura política del continente americano se nota claramente cómo el sistema anterior a la Convención estaba diseñado para Estados que no cumplían con los estándares de ser Estados de Derecho y democráticos. En cambio, a partir del nuevo sistema, se modifica el propósito de la protección de los derechos humanos con la finalidad de reparar violaciones aisladas de derecho humanos cuando el sistema nacional ha sido ineficaz y, por lo tanto, representa un enfoque más jurídico de los derechos humanos. No obstante, ello no quiere decir, en modo alguno, que el sistema interamericano de protección de los derechos humanos como un todo, fuera concebido únicamente para Estados no democráticos, posición que ha sido levantada en algunos foros internacionales y que constituye una verdadera falacia (González \& Picolitti, s.f., p. 8). Tampoco quiere decir que después de la Convención Americana se deje de lado el sistema de investigaciones generales y sistemáticas por medio de la emisión de informes sobre países.

\section{El proceso de denuncias individuales}

El proceso ante la Comisión se desarrolla sobre la base de denuncias individuales a partir de violaciones a derechos humanos contemplados en alguno o algunos de los distintos instrumentos regionales (tratados y convenciones interamericanas). Las partes del proceso ante la Comisión son: la persona peticionaria (cualquier persona o grupo de personas; no necesariamente tiene que ser la víctima ni sus familiares, aunque generalmente coinciden) y el Estado o Estados demandados.

En situaciones muy especiales -casos graves y urgentes- la Comisión puede realizar una investigación, previo consentimiento del Estado demandado- tan solo con la presentación de una petición o comunicación que reúna los requisitos formales de admisibilidad (Artículo 48.2 de la Convención Americana). 
El procedimiento ordinario de peticiones o comunicaciones individuales consiste, fundamentalmente, en cinco etapas bien determinadas en los artículos 48 a 51 de la Convención Americana, a saber: admisibilidad; investigación de los hechos a partir de información que le presenten las partes; solución amistosa, en caso de que proceda; emisión del informe provisional del artículo 50 y envío del caso a la Corte. En caso de que la Comisión decidiera no enviar el caso a la Corte, la etapa final sería la emisión y publicación del informe definitivo del artículo 51, el cual puede ser publicado ${ }^{22}$.

De esas etapas, la de admisibilidad es una de las más importantes porque refleja el sistema más amplio de protección que existe, ya que no es requisito que la persona peticionaria deba ser víctima o familiar de la víctima como se exige en todos los sistemas de quejas individuales internacionales, sino que la petición la puede plantear cualquier persona o grupo de personas (artículo 44 de la Convención Americana). Claro está, como en todos los casos individuales, es un requisito sine qua non, el agotar primero los recursos de la jurisdicción interna, es decir, aquellos que sean eficaces y expeditos en los términos del artículo 25 de la Convención Americana (aquel recurso sencillo y rápido que ampare contra actos que violen derechos fundamentales reconocidos en la Constitución, la Ley o la Convención Americana; es decir, el recurso de amparo, hábeas corpus o hábeas data, según sea el caso).

Cabe indicar que no en todos los casos deben agotarse los recursos internos. En situaciones muy especiales, puede obviarse ese requisito; a saber:

- cuando no exista en la legislación interna el debido proceso legal para la protección del derecho o derechos que se alega han sido violados;

- cuando no se haya permitido al presunto lesionado en sus derechos el acceso a los recursos de la jurisdicción interna, o haya sido impedido de agotarlos;

- cuando haya retardo injustificado en la decisión sobre los recursos mencionados;

- cuando existiere un temor generalizado en el Estado demandado para plantear casos de derechos humanos por parte de abogados defensores en esa materia;

- cuando no hubiere asistencia letrada gratuita en materia penal.

Los otros dos requisitos de admisibilidad son: que una vez agotados los recursos internos, la persona peticionaria debe presentar la denuncia dentro de los seis meses siguientes a su agotamiento y que la materia objeto de la petición o

22 Sobre la naturaleza de los Informes de la Comisión de los artículos 50 y 51 de la Convención Americana se puede consultar las siguientes opiniones consultivas de la Corte Interamericana: Ciertas atribuciones de la Comisión Interamericana de Derechos Humanos. Opinión Consultiva OC13/93 del 16 de julio de 1993. Serie A. No 13 e Informes de la Comisión Interamericana de Derechos Humanos. Opinión Consultiva OC-15/97 del 14 de abril de 1997. Serie A. No. 15. 
comunicación no esté pendiente de otro procedimiento de arreglo internacional (litis pendencia).

Una vez que la Comisión hace un estudio de admisibilidad, emite un informe de admisibilidad o de inadmisibilidad, según sea la situación. Si se declara la admisibilidad, la Comisión se puede poner a disposición de las partes para que puedan discutir la posibilidad de llegar a una solución amistosa (Artículo 48.1.f. Convención Americana), posibilidad que puede ser planteada en cualquier etapa del proceso ante la Comisión, pero la misma debe vigilar porque el eventual arreglo amistoso sea acorde con el respeto a los derechos humanos contenidos en la Convención Americana.

Una vez declarada la admisibilidad y habiendo recibido informaciones del Estado demandado y de la parte peticionaria, la Comisión inicia la etapa de investigación de los hechos mediante un examen del asunto planteado, para cuyos efectos, todas las partes tendrán conocimiento de las actuaciones procesales, las cuales le proporcionarán todas las facilidades necesarias. La Comisión puede, incluso, solicitarles a las partes cualquier información pertinente y recibir escritos y exposiciones verbales; en este último caso, mediante el señalamiento de una audiencia privada junto con las partes.

Finalizada la etapa de investigación y de no haberse llegado a una solución amistosa, la Comisión emite el Informe del artículo 50 de la Convención Americana en el que expone los hechos, sus conclusiones y recomendaciones, para lo cual, le otorga al Estado demandado un plazo para cumplirlas que nunca podrá ser mayor de tres meses. El Informe es transmitido a los Estados interesados, los cuales no pueden publicarlo.

Dentro de ese plazo de tres meses, si el Estado no acata sus recomendaciones, la Comisión puede tomar las siguientes decisiones:

1. Enviar el caso a la Corte Interamericana, lo cual no es automático: primero pide el parecer del peticionario, que además debe incluir la posición de la víctima o sus familiares si fueran distintos del peticionario, argumentación que debe ser presentada dentro del mes de su notificación. Luego, la Comisión considerará esa posición del peticionario, más los siguientes aspectos: la naturaleza y gravedad de la violación, la necesidad de desarrollar o aclarar la jurisprudencia del sistema, el eventual efecto de la decisión en los ordenamientos jurídicos de los Estados miembros y la calidad de la prueba disponible.

2. No enviar el caso a la Corte y emitir, por mayoría absoluta de votos, el Informe del Artículo 51 de la Convención Americana conteniendo su opinión y conclusiones finales y recomendaciones. Este informe, será transmitido a las 
partes, las cuales, en el plazo fijado por la Comisión, informarán sobre el cumplimiento de las recomendaciones. Evaluado el cumplimiento de las mismas, la Comisión decide si publica ese informe, ya sea incluyéndolo en su Informe Anual a la Asamblea General de la OEA o publicándolo en cualquier otro medio que considere apropiado.

\section{La Corte Interamericana de Derechos Humanos}

La iniciativa de crear una Corte Interamericana de Derechos Humanos fue de Brasil, lo que permitió que en la Novena Conferencia Internacional Americana (Bogotá, Colombia, 1948) se adoptara la Resolución XXXI denominada "Corte Interamericana para Proteger los Derechos del Hombre”, en la que se consideró que la protección de esos derechos “debe ser garantizada por un órgano jurídico, como quiera que no hay derecho propiamente asegurado sin el amparo de un tribunal competente", ya que "tratándose de derechos internacionalmente reconocidos la protección jurídica para ser eficaz debe emanar de un órgano internacional". En consecuencia, se encomendó al Comité Jurídico Interamericano la elaboración de un proyecto de Estatuto para la creación de una Corte Interamericana destinada a garantizar los derechos del hombre. Sin embargo, el Comité Jurídico Interamericano, en su Informe al Consejo Interamericano de Jurisconsultos del 26 de septiembre de 1949, consideró que la "falta de derecho positivo sustantivo sobre la materia" constituía "un gran obstáculo en la elaboración del Estatuto de la Corte”, y que lo aconsejable sería que una Convención que contuviera normas de esta naturaleza precediera al Estatuto (Comité Jurídico Interamericano, 1949, p. 108, 197).

Pero fue hasta el 22 de noviembre de 1969 que fue adoptada en San José de Costa Rica la Convención Americana sobre Derechos Humanos, por la que se crea (Capítulo VIII de la Parte II) una Corte Interamericana de Derechos Humanos.

La Asamblea General de la OEA celebrada en La Paz, Bolivia, en 1979, aprobó el Estatuto de la Corte (Resolución 448). El artículo $1^{\circ}$ la define como "una institución judicial autónoma que tiene por objeto la aplicación e interpretación de la Convención Americana sobre Derechos Humanos”.

Los Estados partes en la Convención, en el séptimo período extraordinario de sesiones de la Asamblea General de la OEA (mayo de 1979), eligieron a los primeros siete jueces de la Corte y ésta fue instalada oficialmente en San José, Costa Rica, donde tiene su sede, el día 3 de septiembre de $1979^{23}$.

23 Todos los detalles sobre la instalación de la Corte pueden verse en: Memoria de la Instalación Corte Interamericana de Derechos Humanos, San José, Costa Rica, 1979. 
La Corte en el curso de su Tercer Período de Sesiones, llevado a cabo del 30 de julio al 9 de agosto de 1980, adoptó su Reglamento ${ }^{24}$ y completó los trabajos sobre el Acuerdo Sede concertado con Costa Rica, en el que se estipulan las inmunidades y los privilegios de la Corte, sus jueces y su personal, así como de las personas que comparecen ante la misma.

La Corte está compuesta por siete jueces de la nacionalidad de los Estados miembros de la OEA, pero elegidos a título personal por mayoría absoluta de votos de los Estados Partes en la Convención Americana, de una lista de candidatos propuestos por esos mismos Estados. Son elegidos por seis años y podrán ser reelegidos una vez.

Al igual que la Comisión, la Corte no es un órgano permanente, por lo que todo el trabajo administrativo y logístico lo asume su Secretaría.

\section{Funciones y competencia de la Corte}

De conformidad con la Convención Americana, la Corte ejerce competencia contenciosa (resolución de casos concretos mediante sentencias) y consultiva (emisión de opiniones sobre temas de derechos humanos a interpretar). Estas funciones se distinguen en la materia analizada y las reglas que rigen los respectivos procesos. Al ejercitar su competencia contenciosa, la Corte analiza una demanda específica, establece la veracidad de los hechos denunciados y decide si éstos constituyen una violación a la Convención Americana. El ejercicio de la competencia consultiva es distinto en su contenido y alcances. Primero, al analizar una petición de opinión consultiva, el Tribunal interpreta el derecho internacional, no hechos específicos. Como consecuencia, no existen hechos por demostrar ${ }^{25}$.

Asimismo, mientras que la función contenciosa se resuelve en un proceso judicial en que se ventilan posiciones contradictorias entre las partes procesales (Estado demandado, Comisión Interamericana y la víctima y sus familiares), en la función consultiva tal disputa no existe porque no se refiere a un caso concreto. El ejercicio de la competencia contenciosa de la Corte depende necesariamente de la aceptación previa de su competencia por los Estados Partes que deberán acatar sus sentencias ${ }^{26}$, en cambio, la competencia consultiva del Tribunal no depende del consentimiento de los Estados interesados porque no se ventila caso alguno contra ellos.

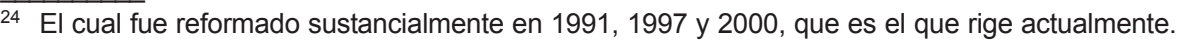

25 La distinción entre la competencia contenciosa y la consultiva de la Corte Interamericana fue señalada por dicho tribunal desde la emisión de su primera opinión consultiva. Corte IDH. "Otros Tratados" objeto de la función consultiva de la Corte (artículo 64 Convención Americana sobre Derechos Humanos), Opinión consultiva OC-1/82 del 24 de septiembre de 1982. Serie A, núm. 1. Párrs, 23, 24, 25, 51.

26 Convención Americana sobre Derechos Humanos, arts. 62 y 68.
} 
Una última diferencia entre ambas competencias se refiere al carácter jurídico de las decisiones emitidas por el Tribunal. En el caso del ejercicio de la competencia contenciosa, los tribunales internacionales emiten sentencias y resoluciones en las que determinan o no la violación al derecho internacional que se denunció y que son vinculantes, tanto para el demandante como para el demandado en el proceso, justamente en virtud de la aceptación previa de que el tribunal es competente para solucionar judicialmente el conflicto que ha surgido entre ellos ${ }^{27}$. Contrariamente, en el caso del ejercicio de la competencia consultiva, la Corte emite una opinión, la cual no tiene las características de una sentencia ejecutable directamente a nivel interno. No obstante, ello no quiere decir, en modo alguno, que las opiniones consultivas no tengan valor jurídico. Por el contrario, la competencia consultiva cumple un papel fundamental en el proceso interpretativo de la Convención Americana (Rodríguez, 1998, p. 482 ss).

Podría decirse que, mientras el acudir a la competencia contenciosa del Tribunal representa un medio para la resolución de conflictos de derechos humanos, el acudir a su competencia consultiva constituye un medio para prevenir conflictos entre los miembros y órganos del sistema interamericano y perfeccionar los instrumentos por medio de los cuales se cumplen sus acuerdos.

\section{El proceso contencioso}

A diferencia de la Comisión Interamericana, donde las partes son los peticionarios (personas o grupos de personas sean o no víctimas o familiares de estas) y el Estado o Estados demandados, en la Corte las partes son, la misma la Comisión Interamericana y los Estados demandados. Sin embargo, con la entrada en vigor del nuevo Reglamento de la Corte, actualmente se permite que, una vez admitida la demanda ante la Corte, las presuntas víctimas, sus familiares o sus representantes tengan capacidad de actuar ante ese Tribunal (locus standi) y, por lo tanto, constituirse como partes (artículo 23.1 Reglamento de la Corte).

En su carácter de órgano jurisdiccional del sistema, la Corte ha conocido más de 30 casos en ejercicio de su competencia contenciosa, que la faculta para resolver cuestiones relativas a la interpretación y aplicación de la Convención Americana mediante la determinación de la violación o no, de los derechos protegidos en ella y ha determinado las reparaciones respectivas (Artículos 62 y63 de la Convención).

La Convención, el Estatuto de la Corte y su Reglamento prevén la existencia de varias etapas en el procedimiento ante la Corte. Es necesario aclarar que estas

$\overline{27}$ Cfr. Corte IDH. Restricciones a la Pena de Muerte (arts 4.2 y 4.4 Convención Americana sobre Derechos Humanos). Opinión Consultiva OC-3/83 del 8 de septiembre de 1983. Serie A No 3. Párr. 32. 
etapas no siempre se cumplen, ya que la misma Convención permite la finalización anticipada del proceso mediante sobreseimiento, solución amistosa, desistimiento o allanamiento ${ }^{28}$.

Sin embargo, en términos generales, los casos ante la Corte se han desarrollado en las siguientes etapas:

a) Fase de excepciones preliminares ${ }^{29}$

Las excepciones preliminares son "defensas procesales" que invocan los Estados demandados que, de ser declaradas con lugar, no sería necesario discutir el fondo del asunto, ni demostrar los hechos ni evacuar prueba porque los motivos de forma o de temporalidad objeto de las excepciones darían término al proceso en favor del Estado. El caso más característico resuelto por la Corte fue el Caso Cayara contra el Perú, donde el Tribunal declaró con lugar la excepción de caducidad de la demanda por haber sido presentada con posterioridad a los tres meses que indica el artículo 51 de la Convención Americana.

No existe una lista taxativa de excepciones preliminares a invocar, sin embargo, a las que más acuden los Estados son las referidas al no agotamiento de los recursos internos (Casos contra Honduras) y caducidad de la demanda (Caso Cayara).

Esta es una fase eventual en el proceso contencioso ante la Corte, pues la oposición de excepciones preliminares es una defensa que puede no ser utilizada por el Estado demandado por ser renunciable. Sin embargo, en la mayoría de procesos ante la Corte los Estados demandados han interpuesto excepciones preliminares.

Es necesario aclarar que la tramitación de las excepciones preliminares no suspende el trámite sobre el fondo del asunto. Sin embargo, en la práctica, la existencia de una fase de excepciones preliminares atrasa la resolución del fondo, pues la Corte debe escuchar los alegatos de las partes y deliberar sobre ellas antes de dictar sentencia.

b) Fase de fondo

Se divide en una fase escrita y otra oral. La escrita se inicia con la presentación de la demanda ante la Corte por parte de la Comisión o de un Estado parte, dentro de los tres meses siguientes a la emisión del Informe del artículo 50 de la Convención Americana. Junto con la demanda, debe aportarse toda la prueba documental y

\footnotetext{
${ }^{28}$ Reglamento de la Corte Interamericana de Derechos Humanos. Arts. 52, 53 y 54.

29 Reglamento de la Corte Interamericana de Derechos Humanos. Art. 36.
} 
ofrecerse la testimonial y pericial correspondiente, indicándose en cada caso, el objeto del testimonio o del peritaje. Por no ser la Corte un tribunal penal, los principios que informan la prueba son bastante flexibles, todo con el fin de que sea aceptada la mayor cantidad de prueba posible, pero descartando aquella que sea abundante o innecesaria.

Si la demanda cumple con todos los requisitos señalados por el artículo 33 del Reglamento de la Corte, el Presidente autoriza su notificación formal al Estado demandado, al cual se le concede un plazo de dos meses para contestarla. En su respuesta, el Estado debe cumplir con los mismos requisitos exigidos para la Comisión en cuanto a la presentación de prueba documental y ofrecimiento de la testimonial y pericial. En caso de que el Estado desee presentar excepciones preliminares, deberá hacerlo en el mismo escrito de contestación.

Una vez que el Estado demandado contesta la demanda, las partes podrían solicitar al Presidente la presentación de otros actos del procedimiento escrito, el cual los autorizará "si... lo estima pertinente" (artículo 38 del Reglamento de la partes si deseaban presentar otros escritos pertinentes, lo que muchas veces era desaprovechado por ellas, ya que los nuevos escritos eran una reiteración de los hechos y argumentos alegados en sus escritos iniciales. Actualmente, en el ejercicio de este derecho -que podríamos llamar "réplica" y "dúplica", respectivamente- se solicita a las partes referirse únicamente a hechos y argumentos nuevos.

Durante la fase oral y pública, la Corte escucha los testimonios y experticias relevantes en el caso $\mathrm{y}$, en último término, los alegatos finales ${ }^{30}$ que las partes en el proceso deseen someter a su consideración. Asimismo, en varios casos la Corte ha fijado audiencias públicas con el propósito de escuchar alegatos respecto de pretensiones específicas, como lo son, por ejemplo, las objeciones o recusaciones a testigos.

Concluido el proceso oral, la Corte delibera en privado sobre el fondo del asunto y dicta sentencia, la cual es definitiva e inapelable ${ }^{31}$. Únicamente procede interpretarla a solicitud de alguna de las partes. Por jurisprudencia, la Corte ha dejado abierta la posibilidad del recurso de revisión, pero para circunstancias muy especiales, como la aparición de hechos nuevos que podrían modificar el resultado final de la sentencia ${ }^{32}$.

30 La presentación de alegatos finales no está sustentada en norma reglamentaria, sino en una práctica seguida por el Tribunal donde se permite a las partes emitir sus conclusiones al final de las audiencias orales sobre el fondo y luego pueden presentarlas en forma escrita dentro de un plazo que fija el tribunal, a partir del envío a ellas, de la transcripción oficial de dichas audiencias.

31 Convención Americana sobre Derechos Humanos, artículo 67.

32 Corte IDH. Caso Genie Lacayo. Resolución de la Corte de 13 de septiembre de 1997. Solicitud de Revisión de la Sentencia de 29 de enero de 1997. 
c) Fase de reparaciones

El Sistema Interamericano es un sistema reparador: una vez que la Corte Interamericana determina que ha existido alguna violación a derechos humanos contenidos en la Convención Americana por parte del Estado demandado, se procede a fijar las consecuencias de ese acto como efecto derivado de responsabilidad internacional de ese Estado. Deviene con ello una escala de responsabilidad que principia con la obligación de restituir el derecho violado, si ello fuera posible (restitución integral del daño). De no ser posible, o en forma colateral, se pueden determinar otras reparaciones como indemnizar por los daños y perjuicios ocasionados, incluyendo "otras formas de reparación".

La jurisprudencia de la Corte ha sido bastante prolija en materia de reparaciones, lo que ha permitido un desarrollo minucioso con se detalla a continuación.

\section{Daños materiales:}

\section{a. Lucro cesante}

En cuanto a la indemnización por lucro cesante, se ha entendido que equivale al monto de los ingresos que las víctimas o sus sucesores recibirían a lo largo de su vida laboral si no hubiese ocurrido la violación a sus derechos ${ }^{33}$.

La base para calcular el lucro cesante es variable y depende de las circunstancias de cada caso. Mientras que en los casos Velásquez Rodríguez y Godínez Cruz se tomó como base para su liquidación el ingreso devengado por las víctimas en el momento de su desaparición proyectado hasta el momento de su jubilación obligatoria según lo dispuesto por la ley interna, partiendo del sueldo que percibían, en los casos Aloeboetoe y otros, Neira Alegría y otros y El Amparo, al no depender las víctimas de un salario fijo, se tuvo que tomar como base para la liquidación, el salario mínimo vital o el valor de la canasta básica alimentaria. A ese monto proyectado a futuro, se le suman los intereses corrientes desde la fecha de los hechos hasta la de la sentencia.

En todos los casos, para efectos de proyectar a futuro los ingresos que percibiría la víctima, se toma en cuenta la expectativa de vida en el país correspondiente.

b. Daño emergente

Normalmente se entienden como los gastos efectuados por las víctimas o sus

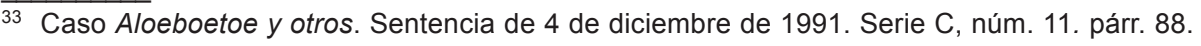


familiares con motivo de sus gestiones para investigar y sancionar los hechos que vulneraron los derechos de las víctimas. En tal sentido, todos los gastos deben ser demostrados con prueba idónea y se le reintegran a la persona que incurrió en los mismos. Pero aun cuando no se haya presentado prueba suficiente, la Corte ha hecho estimaciones compensatorias por gastos incurridos en sus distintas gestiones en el país utilizando el principio de equidad ${ }^{34}$.

Referente a las costas ante la Corte, el hecho de que el individuo tenga capacidad de actuar (locus standi) a partir de la reforma al Reglamento 2000, se cambió el panorama con respecto al reconocimiento de las costas en que incurra el individuo en la protección de sus derechos ya que no está obligado a litigar bajo la égida de la Comisión y puede optar, a su criterio, por la contratación de servicios profesionales privados $^{35}$.

A partir del Caso Garrido y Baigorria, la jurisprudencia de la Corte dio un giro fundamental al reconocer el pago de gastos y costas en todas las etapas del proceso internacional, así como en el proceso interno, ya que reconoció que para que un caso llegue hasta la Corte Interamericana, es indispensable ver como un todo los distintos procesos que se deben establecer hasta llegar a la etapa final ante la Corte.

\section{Daños no patrimoniales:}

Dentro de esta categoría, se incluye en particular, la indemnización por daños morales por medio de distintas formas de satisfacción:

a. Daño moral:

En materia de Derechos Humanos, es quizás el daño que más se justifica resarcir, ya que, resulta evidente y propio de la naturaleza humana, que toda persona sometida a las agresiones y vejámenes que representan la violación de los derechos humanos, experimente un daño moral. Los criterios para su estimación siempre los ha basado la Corte con base en el principio de equidad.

\section{b. Satisfacción no patrimonial:}

Son medidas a cargo del Estado tales como la investigación de los hechos relativos a la demanda, el castigo de los responsables de esos hechos o la reivindicación de la memoria de las víctimas, como se reconoció por primera vez en el Caso Villagrán Morales y otros contra Guatemala respecto a los "Niños de la Calle" que fueron víctimas del Estado.

34 Caso El Amparo, Reparaciones (artículo 63.1 Convención Americana sobre Derechos Humanos), sentencia de 14 de septiembre de 1996. Serie C, núm. 28. párr. 21.

35 Reglamento de la Corte. Art. 23. 
La Corte Interamericana, tiene la facultad de ordenar reparaciones junto con la decisión de fondo, o bien, puede condenar en abstracto y reservar su determinación para una etapa procesal posterior. No existe un procedimiento específico en el reglamento de la Corte para determinar las reparaciones. El nuevo Reglamento únicamente contiene un artículo que dispone que "[c]uando en la sentencia de fondo no se hubiere decidido específicamente sobre reparaciones, la Corte fijará la oportunidad para su posterior decisión y determinará el procedimiento" ${ }^{36}$.

Como el Reglamento no establece un procedimiento específico para las reparaciones, se aplica en forma supletoria y por analogía, las normas procesales referentes al proceso contencioso.

La justificación de esta etapa de reparaciones se fundamenta en la obtención de elementos de prueba suficientes, incluyendo experticias, según el grado de dificultad de cada caso, al número de beneficiarios y a la naturaleza misma de las violaciones. La práctica procesal inicial de la Corte había sido otorgar a las partes un plazo prudencial para que llegasen a un acuerdo o solución amistosa ${ }^{37}$, el cual era estudiado, y en su caso, homologado por el Tribunal ${ }^{38}$. Esa práctica no ha vuelto a ser utilizada por la Corte debido a que prácticamente las partes no han llegado a acuerdos de reparaciones, por lo que se prescinde de esa oportunidad para iniciar la etapa procesal de reparaciones, para lo cual se les brinda a las partes un plazo para que presenten los escritos sobre el alcance, contenido, montos y prueba de las reparaciones.

No obstante, nada impide que aún cuando se inicie esta etapa de reparaciones, las partes pueden llegar a una solución amistosa por su cuenta (art. 56.2 del Reglamento), para lo cual la Corte deberá verificar que el acuerdo sea justo. Ejemplo de ello es el caso Benavides Cevallos contra Ecuador ${ }^{39}$.

Con la aplicación del artículo 23 del Reglamento de la Corte que permitió participación (locus standi) a las víctimas, sus representantes o sus familiares en todas las etapas ante la Corte, se plantea la discusión del papel que deben realizar la Corte y la Comisión Interamericanas en esta fase procesal.

\footnotetext{
$\overline{36}$ Reglamento de la Corte, art. 56.

37 Excepción a esta regla es el caso Godínez Cruz.

38 Reglamento de la Corte, art. 56.2.

39 En el caso Benavides Cevallos, durante la sesión previa a la audiencia sobre reparaciones, tanto el Estado ecuatoriano como la Comisión Interamericana y representantes de los familiares de la víctima, sometieron a consideración del Tribunal un acuerdo firmado previamente entre el Estado y los familiares, el cual fue homologado por la Corte. Caso Benavides Cevallos. Sentencia de 19 de junio de 1998. Serie C No. 38.
} 
Ello ha permitido ver con claridad que, ahora más que nunca, la Comisión puede realizar con mejor desempeño su función de promoción y protección de los derechos humanos, donde sus alegatos no se circunscriban a cuestiones meramente indemnizatorias para las víctimas, sino centrarse en aspectos más generales que sí son parte de su naturaleza institucional, como por ejemplo, tratar cuestiones relacionadas con otras formas de reparación, verbigracia, investigación de los hechos y castigo a los responsables, falta de adecuación de leyes o actos que constituyeron la violación de los derechos establecidos en relación con la Convención Americana, la no repetición de los hechos y, en general, todo aquello que guarde relación con una reparación justa y acorde con el objeto y fin de la Convención. En cambio, la víctima o sus familiares son la parte llamada a demostrar las cuestiones indemnizatorias por tener a su alcance los datos y pruebas que se requieran para ello. La anterior división de funciones se aplicó en forma muy clara en las reparaciones en el caso Castillo Páez contra Perú ${ }^{40}$.

Una vez que ha finalizado la etapa de presentación de escritos sobre reparaciones -lo que podríamos denominar fase escrita- la Corte Interamericana, como práctica procesal, convoca a una audiencia pública para que las partes evacuen sus pruebas testimoniales o periciales y presenten verbalmente sus alegatos sobre las reparaciones.

Posteriormente, se inicia la fase deliberativa de las reparaciones donde se emite una sentencia, de conformidad con el artículo 63.1 de la Convención Americana. Un componente importante de esa sentencia es que, aparte de la determinación de las reparaciones, establece un plazo para que el Estado cumpla con las mismas, que por lo general, es de seis meses.

d) Supervisión y ejecución de sentencias

La Corte generalmente se reserva, en su sentencia de reparaciones, la facultad de supervisar el cumplimiento de su fallo. La supervisión de sentencias es una labor que requiere cuidadoso estudio y detenida consideración. Sin embargo, constituye también la etapa en la que la labor de la Corte alcanza materialmente a aquellas personas para las cuales se ha concebido el sistema de protección a los derechos humanos y en la cual se concretan, de manera más evidente, los beneficios de sus actividades.

Esta etapa consiste en determinar si el Estado encontrado responsable ha cumplido con sus obligaciones en la forma y tiempo previstos. El fundamento de esta etapa de supervisión es consustancial con la naturaleza misma de todo tribunal.

40 Caso Castillo Páez. Reparaciones (Art. 63.1 de la Convención Americana sobre Derechos Humanos). Sentencia de 27 de noviembre de 1998. Serie C No. 43. 
Derecho ₹ Realidad

Los actos que realiza la Corte dentro de su obligación de supervisión, van a depender de la naturaleza de lo resuelto en las sentencias de reparaciones. En unos casos, como los de Honduras, debía determinar el pago del monto de dinero fijado como indemnización a los familiares de las víctimas y que se establecieran los fideicomisos en favor de los beneficiarios menores; en otros casos más complejos, la labor es un poco más detallada, ya que además de supervisar esas mismas obligaciones, debe analizar el informes, reaperturas de escuelas, dispensarios médicos etc., (Cf. Caso Aloeboetoe y otros). Pero quizás sean las otras formas de reparación, que ordene la Corte, las que presenten mayor dificultad en su supervisión, por ejemplo, a la obligación de investigar los hechos y procesar o condenar a los responsables, obligación que ha sido establecida desde los primeros casos resueltos por la Corte y que se ha repetido en todas las sentencias posteriores. A la fecha, en ningún caso se ha dado cumplimiento cabal a esta importante obligación.

Quizás la parte más delicada del sistema de protección de derechos humanos sea la referida a las reparaciones y su cumplimiento por tener relación intrínseca con la eficacia jurídica de las sentencias de un tribunal. Consciente de ello, y para evitar que los fallos de la Corte se quedaran en una sanción de tipo moral, la Convención Americana, en forma atinada dispuso en su artículo 68.2 que "la parte del fallo que disponga indemnización compensatoria se podr[á] ejecutar en el respectivo país por el procedimiento interno vigente para la ejecución de sentencias contra el Estado”.

No obstante, la verdadera fuerza conminatoria de los fallos de la Corte debe radicar en el mismo compromiso de los Estados Parte en la Convención, de cumplir con la decisión de la Corte, tal y como lo dispone el artículo 68.1 de la Convención, que refiere al compromiso de los Estados de cumplir las decisiones de la Corte. Ese compromiso, no puede utilizarse para disminuirle fuerza coercitiva a los fallos, ya que, por el contrario, es una obligación que tienen los Estados Partes de respetar los derechos y libertades contemplados en la Convención de conformidad con el artículo 1.1 de la misma. Precisamente, la Convención Americana adquiere una eficacia de la más alta importancia práctica por operar como derecho interno de aplicación inmediata por los órganos de los Estados Partes y por aplicarse en el marco del Derecho Internacional.

Ello no impide que el artículo 68.1, podría verse reforzado por las legislaciones internas por la obligación que tienen, de conformidad con el artículo 2 de la Convención Americana, de adoptar disposiciones de Derecho interno para garantizar el ejercicio de los derechos y libertades que no estuvieran garantizados por esas legislaciones. En otras palabras, hacer que los fallos de la Corte Interamericana, además de obligatorios, sean ejecutorios. 


\section{El procedimiento consultivo}

La Corte Interamericana está facultada por el artículo 64 de la Convención para emitir consultas con referencia a la interpretación de la Convención o de otros tratados concernientes a la protección de los derechos humanos en los Estados americanos. Según pronunciamientos de la Corte en diversas opiniones, su competencia consultiva se extiende a la interpretación de un tratado siempre que esté directamente implicada la protección de los derechos humanos en un Estado miembro del sistema interamericano ${ }^{41}$. Esta amplia interpretación puede llegar a cubrir tratados que han sido suscritos dentro de sistemas regionales distintos al Interamericano, incluyendo el sistema universal de protección a los derechos humanos. Asimismo, también autoriza a la Corte a interpretar la Declaración Americana de los Derechos y Deberes del Hombre que, a pesar de no ser un tratado en los términos de la Convención de Viena sobre el Derecho de los Tratados, da contenido a varias de las disposiciones contenidas en la Convención Americana y a la Carta de la OEA.

Asimismo, la Corte, a solicitud de un Estado miembro de la Organización, podrá darle opiniones acerca de la compatibilidad entre cualquiera de sus leyes internas y los mencionados instrumentos internacionales. Esta posibilidad es particularmente interesante cuando el Estado solicita la opinión consultiva con respecto a proyectos de ley no implementados aún, con lo cual la Corte asume una especie de consulta de convencionalidad. Esta situación se presentó en la opinión consultiva OC-4/ 84, cuando el Gobierno de Costa Rica solicitó a la Corte una opinión sobre la compatibilidad de algunas eventuales modificaciones a su Constitución Política ${ }^{42}$, así como en la Opinión Consultiva OC-12, respecto a un proyecto de ley sobre doble instancia en materia penal ${ }^{43}$.

En un proceso consultivo, además, la Corte generalmente invita a todos los Estados y órganos legitimados para que presenten sus observaciones escritas sobre el asunto que ha de resolver.

En su opinión consultiva OC-1/82, la Corte Interamericana estableció que la amplitud de términos en que está formulada su competencia en materia consultiva no implica una ausencia de límites en el ejercicio de esta función y ha sido especialmente

$\overline{41}$ Corte IDH. "Otros Tratados" objeto de la función consultiva de la Corte (artículo 64 Convención Americana sobre Derechos Humanos), Opinión consultiva OC-1/82 del 24 de septiembre de 1982. Serie A, núm. 1. Punto resolutivo primero.

42 Propuesta de Modificación a la Constitución de Costa Rica relacionada con la naturalización. Opinión Consultiva OC-4/84 del 19 de enero de 1984. Serie A. No 4.

43 Compatibilidad de un Proyecto de Ley con el artículo 8.2.h. de la Convención Americana de Derechos Humanos. Opinión Consultiva OC-12/91 de 6 de diciembre de 1991. Serie A No. 12. 
cuidadosa al analizar si debe o no absolver una consulta específica y el impacto que su actuación tendrá en el marco general del sistema interamericano y particularmente sobre individuos. De esta manera, la Corte ha establecido que no absolverá consultas que tengan como efecto debilitar o duplicar su función contenciosa o "alterar, en perjuicio de la víctima, el funcionamiento del sistema de protección previsto por la Convención" ${ }^{44}$.

\section{Las medidas provisionales}

Un campo que requiere particular estudio es el referido a la potestad del Tribunal de requerir, a solicitud de la Comisión o motu propio, la adopción de medidas urgentes o provisionales, potestad que le es otorgada por el artículo 63.2 de la Convención, que establece:

[e]n casos de extrema gravedad y urgencia, y cuando se haga necesario evitar daños irreparables a las personas, la Corte, en los asuntos que esté conociendo, podrá tomar las medidas provisionales que considere pertinentes. Si se tratare de asuntos que aún no estén sometidos a su conocimiento, podrá actuar a solicitud de la Comisión.

Las medidas adoptadas por la Corte han revelado ser un instrumento de excepcional importancia en la protección de eventual material probatorio ante la Corte y de la vida e integridad personal de testigos en los procesos que ante ésta se desarrollan.

La extensa práctica de la Corte en materia de medidas provisionales ha permitido también determinar ciertos problemas en relación con la aplicación de estos mecanismos. Uno de ellos, es el referido a la situación que se presenta cuando las medidas se solicitan con respecto a un asunto que no se encuentra en trámite ante la Corte. Esta potestad ha sido vista como un gran avance en el derecho procesal de los derechos humanos. Su valor radica en que los derechos que puedan ser violados están protegidos en una etapa anterior a la conclusión del procedimiento ante la Comisión Interamericana. Sin embargo, en este supuesto, la Corte no cuenta con amplio material probatorio respecto de la existencia de la situación de extrema gravedad y urgencia y actúa otorgando a la solicitud de la Comisión un alto valor presuntivo.

La preocupación básica con respecto a las medidas provisionales es la prolongación excesiva de las mismas, lo que desvirtúa su naturaleza y, a la postre, resta efectividad

\footnotetext{
44 Compatibilidad de un Proyecto de Ley con el artículo 8.2.h. de la Convención Americana de Derechos Humanos. Opinión Consultiva OC-12/91 de 6 de diciembre de 1991. Serie A No. 12.párr. 24.
} 
a un mecanismo concebido como una herramienta de excepción. En efecto, las medidas provisionales, como su nombre lo indica, deben tener un carácter temporal.

La Comisión Interamericana también puede adoptar medidas de carácter preventivo cuando el caso está en su conocimiento y responden a los mismos presupuestos de las medidas provisionales de la Corte, solo que se le conocen con el nombre de medidas cautelares (artículo 25 Reglamento de la Comisión).

\section{El futuro del Sistema Interamericano}

El futuro del Sistema Interamericano está íntimamente ligado con el de la Comisión y la Corte, todo lo cual ha desembocado en una iniciativa de "fortalecimiento" que inició como proceso de "reforma" a instancias Secretario General de la OEA, señor César Gaviria Trujillo en 1996 pero que, luego del impase en que quedó sumido, fue retomado por la Corte y el Gobierno de Costa Rica a partir de 1998. Dentro de ese marco, Costa Rica promovió un debate más amplio, menos defensivo y más constructivo que el de 1996, lo que incidió en un proceso de fortalecimiento, más que de reforma, con la inclusión de todos los órganos del sistema y la convocatoria a organizaciones de la sociedad civil, legisladores, universidades y demás consorcios de entidades involucradas con el quehacer de la promoción y protección de los derechos humanos en la región.

Ello permitió poner a prueba el estatus consultivo de las ONG ante la OEA a lo largo de un ciclo de consultas mediante consorcios de agrupaciones nacionales y regionales que han tenido un papel fundamental en todo el proceso, el cual se caracterizó por las siguientes etapas impulsadas a partir de finales de 1998: la celebración de la semana de Derechos Humanos en Costa Rica; la convocatoria y celebración del Trigésimo Aniversario de la Convención Americana sobre Derechos Humanos, Cuadragésimo de la Comisión Interamericana y Vigésimo Aniversario de la Corte Interamericana de Derechos Humanos, actividad que fue considerada acto oficial del Sistema Interamericano de Derechos Humanos en noviembre de 1999; realización de un diálogo informal de Cancilleres sobre el tema del fortalecimiento del Sistema en que participaron las delegaciones de los veintiséis países americanos y el Secretario General de la OEA, en la que se conformó un Grupo de Trabajo Ad-Hoc que presentó luego, en febrero de 2000, un plan de acción para el fortalecimiento y desarrollo del Sistema Interamericano de Derechos Humanos que incluía, entre otros, dotación de presupuesto adecuado para los órganos del sistema y un proyecto de Protocolo a la Convención Americana para otorgarle a las víctimas de violaciones de derechos humanos, jus standi ante la Corte Interamericana. Como se sabe, este último paso todavía no ha sido dado por la Asamblea General de la OEA. 
Derecho $₹$ Realidad

Esa apretada síntesis de iniciativas, desembocó con la organización y realización de la XXXI Asamblea General de la Organización de los Estados Americanos, en San José, Costa Rica, en junio de 2001, cuyo tema central estuvo dedicado al fortalecimiento del Sistema Interamericano de Derechos Humanos. En esa oportunidad, se abrieron más espacios para que las organizaciones de la sociedad civil pudieran manifestarse más ampliamente con sus pliegos de propuestas que habían sido elaboradas mediante un trabajo de reuniones nacionales y regionales en forma paralela a todo el proceso de fortalecimiento del sistema interamericano.

Hoy, la responsabilidad final de asumir los retos de un fortalecimiento real del Sistema Interamericano descansa en los órganos políticos de la OEA y, especialmente, en la Asamblea General. La Comisión y la Corte ya hicieron lo propio modificando y armonizando sus reglamentos permitiéndole capacidad de actuar a las víctimas ante la Corte, flexibilizando criterios de envío de casos al Tribunal y reduciendo ostensiblemente los plazos durante las distintas fases procesales ante la Comisión y la Corte.

\section{Conclusiones}

1. El funcionamiento del sistema interamericano de protección de derechos humanos mediante los dos órganos de protección creados para esos efectos ha permitido desarrollar una práctica que hoy se encuentra en proceso de revisión y evaluación.

2. Actualmente se pueden determinar tres principales problemas o desafíos en cuanto a su funcionamiento, a saber: estructurales, normativos y procesales.

3. Los problemas estructurales tienen que ver con las dificultades de que Estados anglosajones ratifiquen la Convención Americana y acepten la competencia de la Corte, por lo que el sistema en su amplitud, parece ser más un sistema latinoamericano que interamericano. Es por ello que en cada Asamblea General de la OEA se insiste en la importancia de universalizar el sistema.

4. Los problemas normativos tienen que ver con que se suele comentar que la Convención Americana únicamente protege derechos civiles y políticos, ya que siguió el sistema de la Convención Europea de Derechos Humanos que no había incluido protección para los derechos económicos, sociales y culturales. Solamente existe en la Convención Americana una escueta referencia a la protección de derechos económicos, sociales y culturales en el artículo 26. Dicho vacío fue llenado aparentemente con la promulgación del Protocolo de San Salvador, el cual entró en vigor recientemente. Lamentablemente, la entrada en vigor del Protocolo de San Salvador no es, en modo alguno, la panacea de todos los problemas que atañen a los derechos económicos, sociales y culturales. Bástenos leer su artículo 19, "Medios de Protección”, para enterarnos de que 
únicamente representa un esfuerzo a medias para proteger el derecho del trabajador a organizarse en sindicatos y el derecho a la educación. Cualquier otro derecho contemplado en dicho Protocolo (Vgr. derecho al trabajo, derecho a huelga, derecho a la seguridad social, derecho a la salud, derecho a un medio ambiente sano, etc.), no puede ser objeto de la aplicación del sistema de peticiones individuales regulado en la Convención Americana, sino únicamente de la presentación de informes. Sin embargo, la opción de aplicar el artículo 26 de la Convención Americana como medio autónomo de violación de derechos económicos, sociales y culturales ya está siendo ensayada por la Comisión Interamericana. Así se colige del Caso 12.249 referente al reclamo que realizan personas viviendo con VIH/SIDA en El Salvador por la falta de medicamentos antirretrovirales (Comisión IDH, 2001).

5. Los problemas procesales van desde la lentitud en la resolución de los casos ante la Comisión y la Corte, que duran varios años como promedio en cada órgano ${ }^{45} / 46$, hasta la necesidad de que se permita a las víctimas llevar el caso directamente ante la Corte (jus standi), sin tener que depender para ello de la decisión de la Comisión Interamericana. Para reducir tan largos lapsos de tiempo puede pensarse en varias alternativas, desde resolver los problemas presupuestarios de la Comisión y de la Corte para que sesionen con mayor regularidad, hacer de ambos, órganos permanentes o hasta crear mecanismos para eliminar la duplicidad de los procesos y evacuación de pruebas en ambas instancias. Un primer paso ya lo han dado la Corte y la Comisión Interamericanas, las cuales incluyeron en sendas reformas a sus Reglamentos en el año 2000, la reducción de algunos plazos procesales. Respecto al jus standi, existe un proyecto de Protocolo Adicional a la Convención Americana en ese sentido.

6. Las medidas provisionales ante la Corte es, quizás, el mecanismo más utilizado y eficaz que existe dentro del sistema interamericano. En los últimos años se ha incrementado su utilización con efectos verdaderamente satisfactorios. No obstante, es un mecanismo que debe ser correctamente utilizado para evitar que los efectos para los cuáles fue diseñado se diluyan y deje de cumplir su cometido. El mayor problema que se presenta en la actualidad es que las medidas provisionales que la Corte ha tomado últimamente se han vuelto prácticamente

$\overline{45}$ Guardando las diferencias en cuanto a dificultad en la determinación de los hechos, prueba, etc., el Caso Paniagua Morales y otros contra Guatemala ingresó a la Comisión el 10 de febrero de 1988 y fue enviado a la Corte Interamericana el 18 de enero de 1995 (casi 5 años después). Contrasta con esta situación el Caso Cesti Hurtado contra el Perú, el cual fue sometido a la Comisión el 7 de marzo de 1997 y se envió a la Corte el 9 de enero de 1998 (menos de 9 meses).

46 Un caso promedio puede ser el Caso Caballero Delgado y Santana, el cual fue sometido a la Corte Interamericana el 24 de diciembre de 1992, la sentencia de fondo se dictó tres años después (8 de diciembre de 1995), la sentencia de reparaciones es del 29 de enero de 1997. 
Derecho ₹ Realidad

permanentes debido a que la Comisión no envía el caso a la Corte y a dificultades para dar seguimiento a las medidas adoptadas.

7. Problemas de seguimiento al cumplimiento de sentencias de la Corte y de resoluciones de la Comisión. Esta situación responde a la necesidad de establecer medios de coacción para que los Estados, con base en el principio de buena fe conforme al cual ratificaron la Convención Americana, cumplan con las resoluciones de la Comisión y las sentencias del Tribunal (pacta sunt servanda), so pena de poner en la picota la eficacia jurídica de dichas resoluciones y del mismo sistema interamericano de protección de derechos humanos.

8. Existe poca legislación interna para implementar el artículo 68.2 de la Convención Americana que establece la posibilidad de ejecutar las sentencias de la Corte Interamericana mediante el procedimiento interno para ejecución de sentencias contra el Estado (Rodríguez, 1998). Como medio alterno para el mejoramiento de la eficacia jurídica de los fallos de la Corte Interamericana y, específicamente, de las que establecen reparaciones, debe dársele contenido, mediante la creación de leyes procesales internas, a la norma del artículo 68.2 que dice: "La parte del fallo que disponga indemnización compensatoria se podrá ejecutar en el respectivo país por el procedimiento interno vigente para la ejecución de sentencias contra el Estado" (resaltado no es del original).

9. El mejoramiento y reforma del sistema interamericano de protección de derechos humanos, no es algo que deba verse desde una única óptica: la reforma a los instrumentos interamericanos. Por el contrario, hay muchas vías de realizar actividades para que los órganos de protección apliquen la Convención Americana y la interpreten de manera tal que se pueda obtener mejor provecho de la misma. Mayor coordinación entre la Corte y la Comisión cuando realicen reformas a sus reglamentos en el futuro, mayor utilización de opiniones consultivas para aclarar puntos que requieran ser interpretados (efecto de cosa interpretada) y una voluntad política de los Estados, son sólo algunas de las muchas herramientas a disposición de las partes interesadas, sin tener que recurrir a complejas reformas generales cuyo resultado podría ser contraproducente.

Es indispensable, para reformar integralmente un sistema de protección de derechos humanos, que el mismo se encuentre en un grado de madurez cuya práctica pueda llevarnos a la conclusión de que el mismo se ha convertido en un obstáculo para el desarrollo progresivo de los derechos humanos, situación que no se ha dado en el sistema interamericano, el que, por el contrario, tiene bastantes aristas que aún no ha sido posible explotar, ya que hay muchos derechos protegidos en la Convención Americana que no han sido objeto de estudio por parte de la Corte. 
Por otra parte, si queremos hablar de fortalecimiento del sistema interamericano de derechos humanos con responsabilidad es menester que los órganos políticos de la OEA y los Estados miembros dejen de mantener el doble discurso que ha caracterizado las discusiones presupuestarias, donde por un lado, manifiestan compromiso con los órganos de protección, pero cuando deben aprobar su presupuesto anual no les otorgan los niveles adecuados ni para mantener el trabajo regular, lo que los obliga a recortar actividades, sesiones de trabajo, etc.

Fortalecer el sistema interamericano lleva implícito, ante todo, conocerlo, utilizarlo, promocionarlo. Pero más que eso, su fortalecimiento podría estar en su propio debilitamiento. La mejor forma de proteger los derechos humanos en las Américas es mediante una efectiva protección hacia lo interno, mejorando los canales de acceso a la justicia y modernizando los sistemas de administración de justicia. En el tanto en que los Estados adecuen a su legislación interna las normas de la Convención Americana (artículo 2), así como los criterios jurisprudenciales y de interpretación vertidos por los órganos interamericanos, se podría alcanzar niveles de protección cada vez más satisfactorios y la utilización del sistema interamericano sería cada vez menor debido a una mejor promoción y divulgación que lo pudiera mantener como una vía de solución verdaderamente excepcional.

\section{Referencias}

Comisión IDH. (2001). Informe sobre admisibilidad 29/01.

Comité Jurídico Interamericano. (1949). Recomendaciones e Informes. S.1.: s.n.

Corte IDH. (1998, 8 de marzo). Caso Paniagua Morales y otros. Sentencia. Punto resolutivo 3 .

González, F. \& Picolotti, R. (s.f.). Derechos Humanos y la Organización de Estados Americanos 1996-1997. International Human Rights Law Group, 8.

Nieto, R. (1993). Introducción al sistema Interamericano de Protección a los Derechos Humanos. Bogotá: Temis, Instituto Interamericano de Derechos Humanos.

Nikken, P. (1987). La protección internacional de los derechos humanos: su desarrollo progresivo. Madrid: Civitas.

Rodríguez, V. M. (1998). La Ejecución de Sentencias de la Corte Interamericana de Derechos Humanos. En: J. E. Méndez \& F. Cox (ed.). El futuro del Sistema Interamericano de Protección de los Derechos Humanos. (p. 482 ss). San José, Costa Rica: Instituto Interamericano de Derechos Humanos. 